\title{
Diagnóstico y tratamiento de la otitis media secretora infantil: recomendaciones CODEPEH 2016
}

\section{Diagnosis and treatment of otitis media with effusion: 2016 CODEPEH recommendations}

\section{Palabras clave}

Otitis media secretora, tubos de drenaje, adenoidectomía, guía de práctica clínica.

\section{Keywords}

Otitis media with effusion, tympanostomy tubes, adenoidectomy, clinical practice guideline.

\section{Introducción ${ }^{1}$}

La otitis media secretora (OMS) se define por la presencia de un fluido en el oído medio, sin acompañarse de síntomas o signos de infección aguda (Stool et al., I994; Antolí-Candela et al., 2013). Se pueden encontrar varios sinónimos en la literatura como "otitis media serosa" u "otitis media seromucosa". Tras la revisión bibliográfica llevada a cabo, en el presente documento se ha optado por el término "otitis media secretora", dado que es la terminología más frecuente en relación con esta entidad clínica.

Este tipo de otitis es diferente de la otitis media aguda (OMA), cuyas manifestaciones se caracterizan por una historia de inicio agudo, acompañado habitualmente de dolor, fiebre y, en ocasiones, de supuración.

\section{Faustino Núñez Batalla \\ $<$ fnunezb@uniovi.es>}

Presidente de la CODEPEH. Servicio ORL, Hospital Universitario Central de Asturias-Oviedo. Sociedad Española de Otorrinolaringología

\section{Carmen Jáudenes \\ Casaubón}

<direccion@fiapas.es>

Vocal de la CODEPEH. Directora de la Confederación Española de Familias de Personas Sordas (FIAPAS)

\section{José Miguel Sequí Canet}

Vocal de la CODEPEH. Jefe de Servicio de Pediatría, Hospital de Gandía-Valencia. Asociación Española de Pediatría.

\section{Ana Vivanco Allende}

Vocal de la CODEPEH. Servicio de Pediatría, Hospital Universitario Central de Asturias-Oviedo.

Asociación Española de Pediatría.

\section{José Zubicaray Ugarteche}

Vocal de la CODEPEH. Servicio ORL Infantil, Complejo Hospitalario de Navarra-Pamplona. Sociedad Española de Otorrinolaringología.

\footnotetext{
I. El presente documento de Recomendaciones CODEPEH 2016 ha sido elaborado en el marco del proyecto sobre el Diagnóstico y Tratamiento de la Otitis Infantil para la prevención de alteraciones y retrasos en el desarrollo cognitivo, lingüístico y psicosocial del niño, que ha sido desarrollado por la Confederación Española de Familias de Personas Sordas-FIAPAS, en colaboración con la Comisión para la Detección Precoz de la Sordera Infantil-CODEPEH, con la coorganización del Real Patronato sobre Discapacidad.
}

Nota del editor: este artículo ha sido publicado en Núñez, F. et al. (20I6): "Diagnóstico y tratamiento de la otitis media secretora infantil: Recomendaciones CODEPEH 20I6". Revista FIAPAS, octubrenoviembre-diciembre $2016, \mathrm{n}^{\circ} \mathrm{I} 59$.
Para citar:

Núñez, F. et al. (20I7): "Diagnóstico y tratamiento de la otitis media secretora infantil: recomendaciones CODEPEH 20I6". Revista Española de Discapacidad, 5 (I): I69-I93.

Doi: <https://doi.org/I0.5569/23405IO4.05.OI.IO> 
Existe una alta incidencia en la edad infantil. Hasta un $90 \%$ de los niños desarrollan una OMS antes de la edad escolar y sufren cuatro episodios anuales por término medio (Mandel et al., 2008: 49I-499).

La OMS se presenta habitualmente en dos contextos: de forma espontánea por un funcionamiento anómalo de la trompa de Eustaquio, o bien, tras haber padecido una otitis media aguda, como una reacción inflamatoria, especialmente en edades comprendidas entre los seis meses y los cuatro años de edad (Paradise et al., I997: 318-333). Si se hacen reconocimientos escolares en busca de otitis media secretora, se encuentra fluido en el oído medio en uno de cada ocho niños de cinco a seis años de edad. Sin embargo, la prevalencia de la otitis media secretora en niños con síndrome de Down o paladar hendido es mucho mayor, de un $60 \%$ a un $85 \%$ (Maris et al., 20I4: I3I9I325). La mayoría de los episodios se resuelven espontáneamente a los tres meses, pero entre el $30 \%$ y el $40 \%$ de los niños tendrán episodios repetidos y, en el $5 \%$-Io \% de los afectados, la OMS tendrá una duración mayor de un año (Williamson et al., I994: 930-934).

La OMS es la causa más frecuente de sordera infantil en los países desarrollados. La hipoacusia permanente relacionada con las secuelas postotíticas tiene una prevalencia de 2 a 35 por I0.000 (Qureishi et al., 20I4: I 5-24).

La persistencia del fluido en la caja timpánica condiciona que disminuya la movilidad de la membrana, ofreciendo un obstáculo a la conducción sonora (Williamson, 2002: 469476). Al menos la cuarta parte de los episodios de otitis secretora persisten más de tres meses y se pueden asociar con hipoacusia, problemas vestibulares (equilibrio), bajo rendimiento escolar, problemas de comportamiento, otitis medias agudas de repetición y pérdida de calidad de vida. Menos frecuente es que se origine un daño estructural en la membrana timpánica o en los huesecillos del oído medio que requiera una intervención quirúrgica en el futuro (Rosenfeld y Kay, 2003: I645-I657; Rosenfeld et al., 2013: $\mathrm{S}_{\mathrm{I}-\mathrm{S}} 35$; Jung et al., 20I3: EI22-EI43).
La incidencia de la OMA es cinco veces superior en los niños con otitis secretora en los que, además de los síntomas propios de la misma, se añaden otalgias con fiebre que provocan sufrimiento físico, estrés emocional y preocupación en los padres (Rosenfeld et al., 2000: 585-592).

El impacto de la otitis media secretora es superior en niños que presentan comorbilidades de diversa entidad. También existe una mayor tendencia a presentar retrasos en el desarrollo cuando la otitis secretora se asocia a una serie de trastornos, como factores sensoriales, cognitivos o de comportamiento, que provocan un mayor riesgo de retrasos o alteraciones en los niños que los presentan (Tabla I). Por lo que es de gran importancia identificar estos casos y actuar terapéuticamente de forma más precoz.

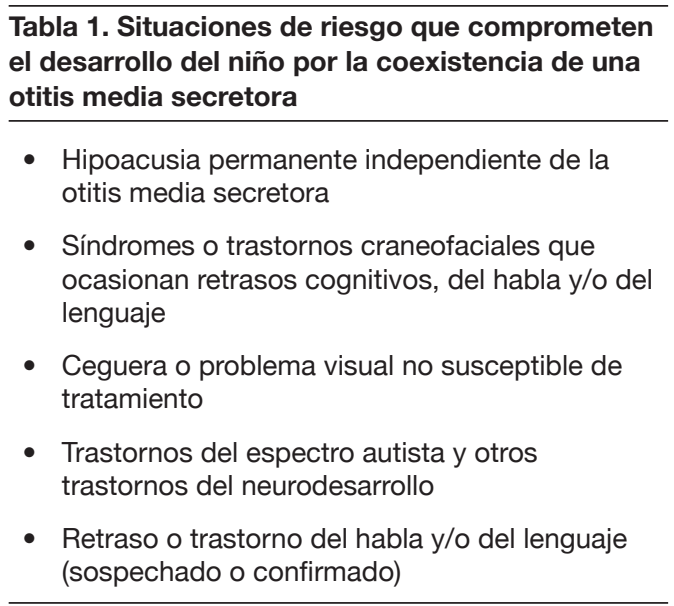

Fuente: modificada de Rosenfeld, 2016.

A pesar de la alta incidencia y prevalencia de la OMS, existen evidencias de que sólo una minoría de los profesionales sigue las recomendaciones que recogen las guías de manejo clínico de la enfermedad. El escaso uso de la otoscopia neumática en el diagnóstico, la falta de exploraciones audiométricas de los niños que presentan una otitis secretora crónica o el uso inapropiado de antibióticos para tratarla, son los problemas más frecuentes (Rosenfeld et al., 2016: SI-S4I). 
La CODEPEH considera necesario revisar el manejo de la OMS infantil, establecer una serie de recomendaciones para tratar de contrarrestar la variabilidad clínica constatada en la actitud ante ésta y llamar la atención acerca de la existencia de una población de niños que presentan patologías previas con especial susceptibilidad de sufrir o agravar un retraso en el desarrollo como consecuencia de una OMS. Esta revisión es aplicable para los niños con OMS entre los dos meses y los doce años de edad, con o sin trastornos en su desarrollo o comorbilidades que predispongan a padecerla (Rosenfeld et al., 2004: S95-Si I 8).

El propósito de este documento es establecer unas recomendaciones dirigidas a todo profesional clínico que diagnostique y trate una otitis media secretora infantil en cualquier medio. Específicamente, las metas son la mejora de la exactitud diagnóstica, la identificación de los niños más susceptibles de sufrir secuelas en su desarrollo secundarias a la misma y orientar a los profesionales, con el fin de conseguir los mayores beneficios terapéuticos a partir de un correcto manejo de la OMS.

\section{Actitud ante una OMS infantil}

\subsection{Actitud ante un niño sin riesgo}

La conducta a seguir ante un niño sin riesgo que presenta una otitis media secretora es establecer una pauta de espera de tres meses antes de tomar otras medidas como derivaciones al otorrinolaringólogo, evaluación audiológica y cirugía. El propósito de esta recomendación es evitar medidas innecesarias y se basa en el hecho de que la otitis secretora tiene una naturaleza autolimitada en la mayoría de los casos, sobre todo en aquellos en los que está precedida por factores desencadenantes comunes como el catarro de vías altas o la otitis media aguda (Bhutta, 20I4: 210-223). Se sabe que del 75\% al $90 \%$ de los casos de OMS tras una otitis media aguda estarán resueltos a los tres meses. Esta pauta de espera es inocua en los niños sin riesgo. Se debe informar a los padres de que el niño experimentará un periodo de peor audición, hasta que la OMS se resuelva, y han de ser instruidos en estrategias indicadas para optimizar la escucha (Roberts et al., 2000: 725735 ; Jáudenes y Patiño, 2007).

La recomendación del periodo de observación de tres meses se basa en la clara preponderancia del beneficio sobre el riesgo y es coherente con otras recomendaciones previas en este sentido, con el objetivo claro de evitar cirugías innecesarias (Stool et al., I994).

\subsection{Actitud ante un niño en situación de riesgo}

Aunque no existen estudios definitivos, es evidente que una otitis media secretora puede afectar de forma más severa a aquellos niños que presentan una comorbilidad (Tabla I) que los ponga en una situación de riesgo o con mayor susceptibilidad de sufrir retrasos en su desarrollo (Ruben, 201 I: 707-7I2).

Los trastornos del desarrollo, de la conducta y los sensoriales no son infrecuentes, por lo que su asociación con las otitis medias secretoras es un problema clínico habitual. La pérdida de audición asociada a la OMS puede empeorar significativamente la evolución de estos niños, lo que hace de la detección y tratamiento de dicha otitis una importante meta. Si se presenta con frecuencia puede degradar la señal auditiva y causar dificultades en el reconocimiento del habla, en el procesamiento superior de las palabras, la comprensión en ambientes ruidosos y la localización espacial de los sonidos (Khavarghazalani et al., 20I6: 456-459).

Ejemplos de lo afirmado son los casos que padecen una hipoacusia permanente preexistente, que verán incrementada la dificultad auditiva debido a las consecuencias de la OMS, con el consiguiente efecto negativo sobre el desarrollo del habla y del lenguaje. De forma similar, los niños con ceguera o alteraciones visuales no tratables dependen más de la audición, haciéndoles susceptibles de presentar desequilibrio, dificultades de 
localización del sonido y retraso en el habla y el lenguaje (Ruben, 2003: 505-5 I4).

Los niños con síndrome de Down tienen otitis secretoras más frecuentes y persistentes, con conductos auditivos externos estrechos que pueden impedir valorar la membrana timpánica y el estado del oído medio. Se presenta con una alta prevalencia: el $67 \%$ de los casos presenta OMS al año de vida. A los seis o siete años se incrementa de nuevo la incidencia, con un $60 \%$ de afectados. A partir de los ocho años se observa una tendencia a que dicha prevalencia disminuya. Se acompaña de una hipoacusia leve o moderada (Maris et al., 20I4: I3 I9I325). Además, tienen riesgo de desarrollar una hipoacusia mixta o neurosensorial. Estos riesgos se mantienen a lo largo de la infancia y puede ser necesaria la colocación repetida de tubos de drenaje. En estos casos se recomienda el control audiológico semestral desde el nacimiento, para evaluar el estado del oído medio y limpiar los conductos, además de realizar pruebas audiométricas cuando proceda (Iino et al., I999: I43-I49).

El paladar hendido es una malformación común, con una prevalencia de I de cada 700 recién nacidos. Asocia OMS en casi todos los casos porque las inserciones del músculo tensor veli palatini son anómalas, ocasionando una dificultad en la apertura de la trompa de Eustaquio. La otitis media secretora crónica en estos pacientes da lugar a una hipoacusia transmisiva, cuya severidad se recomienda monitorizar a lo largo de toda la infancia, incluso después de la reparación quirúrgica de la malformación, debido a que su prevalencia no disminuye tras dicho tratamiento (Sheahan et al., 2002: 494-500; Ponduri et al., 2009: 30-38).

La disfunción tubárica no sólo afecta a los niños con paladar hendido y síndrome de Down, también se asocia con otros síndromes craneofaciales y malformaciones del área de cabeza y cuello (Marchisio et al., 2008: 426-432).

Cuando se detecta una OMS en un niño en situación de riesgo, se debe ofrecer la colocación precoz de unos drenajes transtimpánicos (DTT)
(Rosenfeld et al., 20I3: SI-S 35 ). Para los niños a los que no se les ha indicado dicho tratamiento se debe determinar una pauta de controles para monitorizar la OMS y los niveles de audición, dependiendo de sus necesidades individuales. Es aconsejable hacerlo con una periodicidad inferior a los tres meses, que es lo recomendado en niños sin riesgo.

Por todo lo expuesto anteriormente, para los niños en situación de riesgo es recomendable descartar la presencia de una otitis secretora a los I 2 y a los I 8 meses de edad, dado que este es un periodo especialmente importante para el desarrollo del habla y el lenguaje, el equilibrio y la coordinación (Núñez et al., 20I4; Núñez et al., 2016: 45-53).

La hipoacusia leve o moderada, uni o bilateral puede causar dificultades académicas, sociales y conductuales, haciendo de este lapso temporal un periodo crítico para identificar la otitis media secretora y, si es preciso, tratarla. Por ello, en esta población de niños de riesgo, se recomienda la valoración audiométrica utilizando el método que corresponda de acuerdo con la edad del niño, así como con la periodicidad que sea necesaria para poder evaluar la efectividad del tratamiento quirúrgico cuando esté indicado (Rosenfeld et al., 2004: S95-SI I 8).

Esta búsqueda activa de la presencia de una OMS en la población de niños en situación de riesgo no debe ser extendida a la población de niños sin riesgo, donde de forma explícita está desaconsejado el cribado sistemático de la OMS (Simpson et al., 2007).

\subsection{Actitud ante el cribado neonatal alterado atribuible a una OMS}

En caso de que un niño no pase las pruebas de cribado neonatal de la hipoacusia, y se atribuya dicho resultado a la presencia de una otitis media secretora, se recomienda su vigilancia periódica con el fin de reducir la probabilidad de que pase desapercibida o se retrase la detección de una hipoacusia neurosensorial (Calderon y Naidu, I999: 53-84). 
La OMS es una causa importante de hipoacusia moderada transitoria en los recién nacidos que no superan el cribado neonatal de la hipoacusia: en un estudio prospectivo de los fallos en el cribado se halló que un $55 \%$ de los casos presentaba otitis media secretora (Boudewyns et al., 201 I: 799-804).

Sin embargo, aunque la mayoría de ellos tendrá una resolución espontánea, a algunos se les diagnosticará una hipoacusia neurosensorial subyacente. Se ha encontrado que un I I \% de los fallos en el cribado presentan simultáneamente una OMS y una hipoacusia neurosensorial, sin embargo, inicialmente en dos tercios de estos casos se había atribuido el fallo en la prueba de cribado exclusivamente a la OMS (Boone et al., 2005: 393-397).

3. Repercusiones de la OMS sobre la conducta y el desarrollo del niño

El impacto de la otitis media secretora en la calidad de vida es notorio. El $64 \%$ presenta trastornos del sueño, el $49 \%$ trastornos de la conducta, entre el $33 \%$ y el $62 \%$ retraso en el desarrollo del lenguaje y el I $5 \%$ desequilibrio (Brouwer et al., 2005: I03 I-IO4I; Karkanevatos y Lesser, I998: 732-74I).

Cuando un niño tiene una OMS, ésta hace que disminuya temporalmente su audición. Y lo puede hacer de forma repetida a lo largo de los primeros años de vida, pudiendo llegar a tener un efecto nocivo sobre algunas áreas de su desarrollo (cognitivo, comunicativo, socioemocional), su proceso educativo y sus aprendizajes. De hecho, la OMS se relaciona con dificultades del habla y la lectura, respuestas lentas ante estímulos auditivos, vocabulario pobre y problemas de atención. Todo ello explica que, tras la identificación y el correcto tratamiento, el aprovechamiento y rendimiento escolar mejoren sustancialmente (Rosenfeld et al., 20I I: I90I95). Esto es aún más evidente cuando se trata de niños en situaciones de riesgo.
La repercusión de una OMS es de diversa índole y gravedad, dependiendo de circunstancias como el grado de pérdida de audición que genere, la edad y el nivel de lenguaje ya adquirido por el niño.

Si se trata de un episodio de OMS en un niño normoyente, estaremos ante una pérdida auditiva en el límite de poder llegar a ser considerada de grado leve-moderado (25-40 $\mathrm{dB})$. Por contra, si se trata de un niño con una sordera ya instaurada, dependiendo de su grado, a éste se sumará la propia pérdida que provoca la OMS, por lo que su deficiencia de audición se agravará, cuantitativa y cualitativamente. Todo ello será más o menos acusado dependiendo además de si la OMS afecta a un solo oído o a ambos.

Como se ha dicho, otro aspecto que determina el mayor o menor efecto de la OMS son las edades en las que esta entidad clínica aparece con más frecuencia (o-8 años). Los primeros años de vida son críticos para el desarrollo del habla y del lenguaje, así como para la adquisición de herramientas instrumentales para el aprendizaje, como la lectoescritura, además de implicar otras consecuencias sobre los procesos de atención y memoria, así como sobre la conducta (Jáudenes, 2004: 205-208; Torres, 2004a: 23 I-244; Torres, 2004b: 337-349; Villalba, 2004: I 85-204).

También hay que tener en cuenta que si la audición fluctúa con la persistencia de la OMS, esto puede provocar inestabilidad en la conducta del niño que responderá de distinta forma ante iguales estímulos sonoros y verbales, prestará menos atención a dichos estímulos, podrá mostrarse inquieto, etc. (Jáudenes et al., 2006; Jáudenes y Patiño, 2007).

\subsection{Consecuencias según el grado de pérdida auditiva}

Cuando se trata de una OMS sobrevenida en un niño con normoaudición, este tipo de pérdidas inferior a $40 \mathrm{~dB}$ permiten oír gran parte de lo que suena y de lo que se dice en torno a él, pero no todo, dado que puede existir un déficit en 
la discriminación de los rasgos fonéticos de las palabras. También podría haber dislalias, pues no oyen o no discriminan unos fonemas de otros y en el habla los omiten o intercambian. Puede existir asimismo cierto retraso en el desarrollo del lenguaje.

Todo ello puede llegar a afectar al aprovechamiento escolar y a la conducta, ya que se generan problemas de atención y dificultad en la comunicación en espacios contaminados por el ruido ambiente, como pueden ser los espacios de juego y los escolares.

Cuando se trata de niños con deficiencias de audición ya instauradas, por encima de los 40 $\mathrm{dB}$, la presencia de una OMS da lugar a pérdidas auditivas que afectan no sólo a una mejor o peor discriminación fonética, sino a la adquisición de la conciencia fonológica necesaria para el desarrollo cognitivo y lingüístico. E igualmente dará lugar a dificultades en la comunicación en ambientes ruidosos y en intercambios con varias personas a la vez, además de presentar problemas de atención, retrasos en el aprendizaje, así como en el aprovechamiento y el rendimiento escolar (Jáudenes et al., 2006; Jáudenes y Patiño, 2007).

Todas estas situaciones resultan de más envergadura y se prolongan en el tiempo cuanto mayor es la pérdida auditiva de base o si existen situaciones de riesgo añadidas (Tabla I).

\subsection{Consecuencias según la edad y el nivel de lenguaje adquirido}

Cuando se trata de un niño sin lenguaje adquirido (o-3 años), el déficit o la falta de audición da lugar a alteraciones y déficits de la conciencia fonológica y del hábito de escucha. Tiene efectos también sobre el equilibrio y la psicomotricidad, así como sobre los aprendizajes y adquisiciones propias de la primera infancia, además de alteraciones de la conducta.

Si se trata de un niño con lenguaje adquirido (3-I 2 años) se producen asimismo alteraciones y déficits de la conciencia fonológica y del hábito de escucha, efectos sobre el aprendizaje escolar y educativo, alteraciones de la conducta, alteraciones del equilibrio, efectos sobre el acceso a la lectoescritura y sobre el aprovechamiento y rendimiento escolar.

De todos estos efectos que provoca la falta de audición secundaria a la OMS, hay uno en particular que en la inmediatez del momento puede pasar desapercibido y, sin embargo, de no ser vigilado y tratado tiene consecuencias permanentes que se han de destacar. Se trata de señalar las consecuencias que provocan las limitaciones en el acceso a los rasgos fonéticos del lenguaje. La adquisición de la conciencia fonológica contribuye a la instalación y desarrollo de herramientas cognitivas de alto nivel que más tarde aflorarán, como el lenguaje interior, la lectoescritura, el pensamiento verbal, la representación mental, el simbolismo fonético, etc. (Torres, 2016: I4-I7).

Por ello hay que estar muy atento, tanto en el ámbito familiar como en el escolar, a cualquier cambio que se produzca en la conducta de respuesta del niño ante los sonidos y en el interés mostrado por las fuentes que los emiten. Hay que estar pendiente de cualquier modificación en sus hábitos y estrategias de comunicación, de relación social y de juego, así como de cualquier alteración en su habla y en el desarrollo del lenguaje, además de en su comportamiento.

\section{Métodos para el diagnóstico de una OMS infantil}

\subsection{Otoscopia}

En la valoración del oído y, por lo tanto, en el diagnóstico de la OMS, la otoscopia es la técnica más importante (Karma et al., I989: 37-49). Se puede llevar a cabo con el otoscopio convencional, con videoendoscopio (Shiao y Guo, 2005: I497-I502) o con microscopio, que mejora mucho la posibilidad de alcanzar un diagnóstico preciso (Lee, 20IO: I 5 I-I 53 ), 
igualándose al patrón de referencia de la otoscopia neumática.

La otoscopia es una técnica que precisa entrenamiento y experiencia para una correcta valoración del oído (Kaleida y Stool, I992: 433-435). En los niños, sobre todo en los más pequeños, el tamaño del conducto auditivo externo (CAE), el ángulo de la membrana timpánica, más abierto cuanto más pequeño, el llanto y la falta de colaboración del paciente, hacen que algunos oídos patológicos sean interpretados como normales.

Los signos otoscópicos que facilitan el diagnóstico de una OMS son la pérdida de transparencia, el engrosamiento de la membrana y el cambio de tono. Se puede apreciar en ocasiones un nivel hidroaéreo. Es importante diferenciarlo de una otitis media aguda no supurada, siendo en ésta el dolor y los signos inflamatorios las características más importantes.

\subsection{Otoscopia neumática}

La otoscopia neumática es considerada la técnica de referencia (American Academy of Family Physicians et al., 2004: I4I 2-I429). Para su realización se precisa un otoscopio, un espéculo que se ajuste perfectamente al CAE y una perilla para hacer las maniobras de insuflación.

La prueba se realiza haciendo una presión suave sobre la perilla conectada al otoscopio. Si el oído es normal, se ve como la membrana se mueve hacia dentro al apretar la perilla y como vuelve a la posición al dejar de hacer presión. Si existe algún derrame en el oído medio, la movilidad de la membrana se verá disminuida o no se moverá, según la cantidad y la densidad del líquido existente. Si la membrana está inmóvil, incluso, se puede ver un movimiento de las paredes del CAE.

La otoscopia neumática es la primera técnica indicada en el diagnóstico inicial de la OMS, tiene una sensibilidad del $94 \%$ y una especificidad del $80 \%$ en relación a la miringotomía (Shekelle et al., 2002: I-5).

Esta técnica, a pesar de sus numerosas recomendaciones para el diagnóstico de una OMS (Rosenfeld et al., 20I6: $\mathrm{S}_{\text {I-S}} \mathrm{S}_{4} \mathrm{I}$ ), se usa poco en atención primaria por la necesidad de tener material apropiado, a pesar de su bajo coste, y por la dificultad de su aprendizaje, prefiriéndose en este medio el uso de la timpanometría (Abbott et al., 20I4: I8I).

Al ser una técnica subjetiva, su mayor inconveniente es la variabilidad de interpretación entre distintos observadores y que, en casos de OMA, puede producir dolor.

\subsection{Timpanometría}

Es una prueba objetiva que nos dará información de las características dinámicas del estado del oído medio y del complejo tímpanoosicular. Mide la admitancia acústica del oído medio en relación a los cambios de presión en el oído externo (Nozza et al., I992: 442-453). Esta prueba no mide la audición del niño (Group MRCM-cOMS, 2009: 2I-42).

Se trata de un procedimiento fácil de llevar a cabo con un timpanómetro portátil o un timpanómetro de diagnóstico clínico. El resultado es un gráfico de la energía admitida por el tímpano y el oído medio en respuesta al aire a presión introducido en el CAE. La energía acústica es trasmitida al CAE y un micrófono mide el reflejo del sonido mientras la presión varía entre +200 y $-400 /-600 \mathrm{~mm}$ de $\mathrm{H}_{2} \mathrm{O}$.

Es recomendable promover la timpanometría como una herramienta objetiva para el diagnóstico de la OMS, tanto para confirmar los hallazgos de la otoscopia neumática, como para constituir una alternativa a la otoscopia cuando la visualización de la membrana es limitada. Existen recomendaciones precisas a seguir (Tabla 2) para la realización de la timpanometría (Rosenfeld et al., 20I6: SI-S4I). 
Tabla 2. Recomendaciones para la realización de una timpanometría

- Intolerancia del niño a la otoscopia neumática

- Falta de experiencia en la realización de otoscopia neumática

- Dificultad para ver la membrana timpánica por obstrucción parcial de cera

- Dificultad en visualizar la membrana por CAE estrecho o con estenosis

- Dudas en la presencia de OMS por resultados equívocos de la otoscopia neumática

- Necesidad de excluir OMS en niños en situaciones de riesgo

- Necesidad de confirmar OMS antes de la cirugía

Fuente: modificada de Rosenfeld, 20I6.
Para su correcta realización es necesario hacer antes una otoscopia con objeto de descartar oclusiones o procesos infecciosos del oído. La sonda con frecuencias de $226 \mathrm{~Hz}$ ha demostrado ser efectiva para identificar la OMS en niños de edad preescolar y escolar (especificidad del $82-89 \%$ y sensibilidad del 95 -100\%), pero su fiabilidad es menor en edades inferiores a 6-9 meses de vida. Se recomienda el uso de una sonda de I $\mathrm{kHz}$ en las exploraciones en niños menores de esa edad (Núñez et al., 20I4; Núñez et al., 20I 6: 45-53; Mena et al., 2016: 306-3 I4; American Academy of Pediatrics JCoIH, 2007: 898-92 I). La interpretación del resultado se hace sobre unos gráficos (timpanograma), que se obtienen del equipo.

Siguiendo la clasificación de Jerger (Figura I) tenemos tres curvas básicas (Jerger, I970: 3 I I324):

\section{Figura 1. Curvas de timpanometría, según Jerger}

\section{Curva tipo A}

$\mathrm{ml}$

$\underline{2,0}$

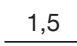

1,0

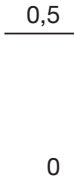

0

0,5

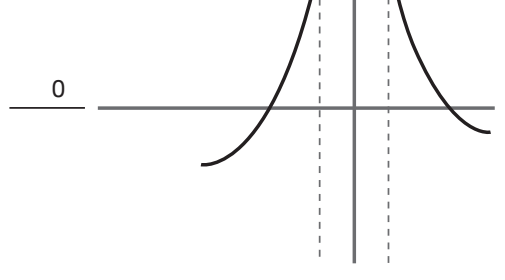

$-400 \quad-200$
Curva tipo B

$\mathrm{ml}$
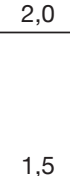

1,0
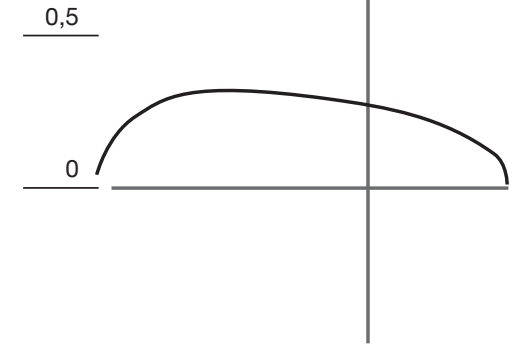

$\mathrm{ml}$

2,0

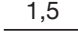

1,0
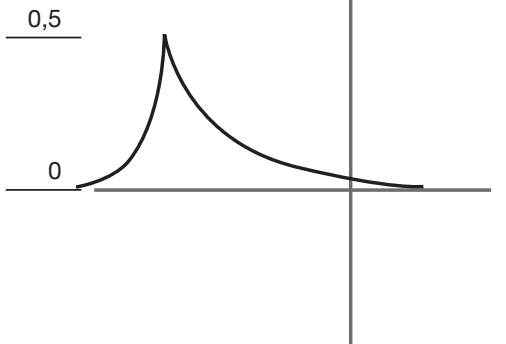

Fuente: Jerger, I970. 
a. Curva tipo A. Es el patrón de normalidad y se caracteriza por tener una forma global "en techo de pagoda" con un pico estrecho, cuyo máximo punto de presión se encuentra entre +50 y - $100 \mathrm{~mm}$ de $\mathrm{H}_{2} \mathrm{O}$, con una amplitud máxima entre I y $2 \mathrm{ml}$.

b. Curva tipo B. Esta curva es una línea casi plana que indica derrame dentro del oído medio.

c. Curva tipo C. Esta curva tiene el pico a más de $\mathrm{I}_{5} \mathrm{omm}$ de $\mathrm{H}_{2} \mathrm{O}$, indicando un gradiente negativo de presión dentro del oído medio.

En niños por debajo de los 6-9 meses es recomendable que los timpanogramas se clasifiquen en normales y anormales, usando la clasificación Baldwin (Figura 2) (Baldwin, 2006: 4I7-427). Se traza una línea vertical desde la línea base al pico de la curva y se determina como normal cuando el pico está por encima de la línea base (pico +), o anormal cuando el pico está debajo de la línea base (pico -). En caso de existir un pico positivo y otro negativo se considerará como normal.

Otro dato importante es la medida del CAE, que suele ser en adultos entre $0,6 \mathrm{cc}$ a I, $5 \mathrm{cc}$ y en niños de 3 a 5 años de 0,4 cc a I, O cc.

Cuando la medida del CAE, en una curva tipo B, el volumen sea superior a estas cifras indicará una perforación timpánica o la presencia de un drenaje (DTT).

\section{Figura 2. Timpanograma con sonda de $1 \mathrm{kHz}$, según clasificación de Baldwin}

$\mathrm{m}$

\section{Pico positivo}

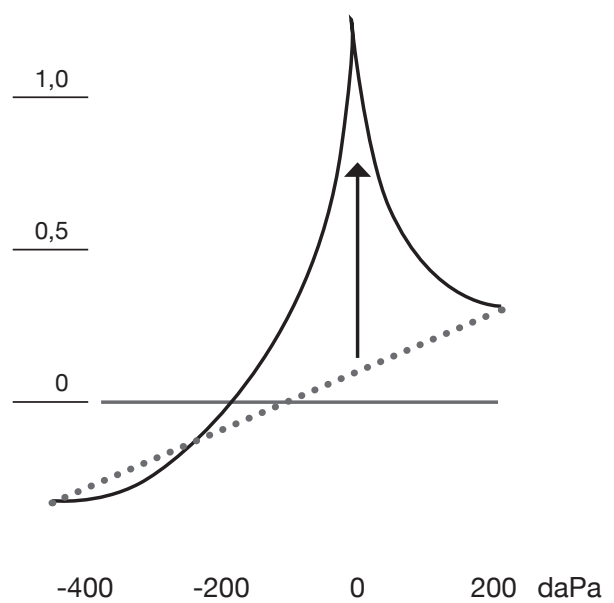

\section{$\mathrm{ml}$}

2,0

\section{Pico negativo}

1,5

1,0

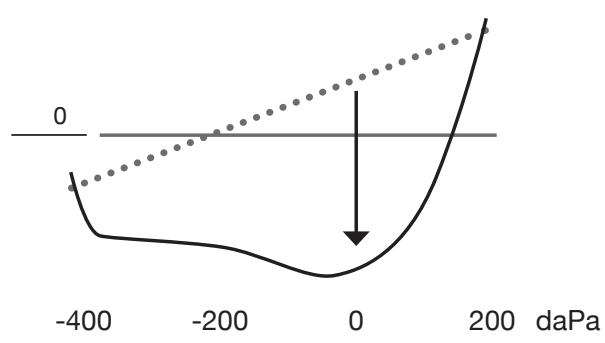

Fuente: Baldwin, 2006. 


\section{Tratamiento médico de la OMS infantil}

Los objetivos principales del tratamiento de la OMS son eliminar la secreción del interior de la caja timpánica, restaurar la audición normal y prevenir, en lo posible, futuros episodios (Klein y Pelton, 20I6; Rosenfeld et al., 20I6: SI-S4I).

Varios medicamentos han sido utilizados para el tratamiento de la OMS, con el doble objetivo de mejorar la calidad de vida del paciente y evitar intervenciones quirúrgicas invasivas. El propósito de este apartado es analizar su eficacia.

\subsection{Esteroides orales y tópicos}

La idea de la utilización de los corticoides se basa en su efecto antiinflamatorio en la rinofaringe y el oído medio. Además, regulan al alza el transporte de sodio transepitelial en el oído medio, promoviendo la eliminación del líquido de la cavidad del oído medio (Principi et al., 2016: 4I5-423).

\section{- Glucocorticoides orales}

Ya en 2004 distintas asociaciones médicas y, posteriormente, las directrices del Instituto Nacional para las directrices de Excelencia Clínica (NICE) desaconsejaron el uso de glucocorticoides orales para el tratamiento de la OMS (American Academy of Family Phisicians et al., 2004: I4I2-I429; NICE, 2008).

Más recientemente, la Agencia para la Investigación y Calidad Sanitaria (AHRQ) examinó la eficacia de los esteroides orales en el tratamiento de la OMS y demostró que no son útiles ni beneficiosos para la resolución del derrame o en la mejora de la pérdida auditiva (Berkman et al., 20I3) y que, añadiendo antibióticos, no mejoran los resultados en comparación con los pacientes de control, que se dejaron sin tratar o se trataron sólo con antibióticos (Thomas et al., 2006; Simpson et al., 2007).
En una revisión sistemática Cochrane de 20 I , en la que se incluían estudios diversos sobre el uso de los glucocorticoides (con o sin antibióticos) para el tratamiento de la OMS en niños, los glucocorticoides orales se asociaron con la resolución de la OMS a las dos semanas de tratamiento, pero no más allá de ese plazo (Simpson et al., 20I I).

Además, en el único estudio que se evaluó la audición, los glucocorticoides orales no mejoraron ésta (Macknin y Jones, I98 5: 329).

Es conocido que los corticoides orales están asociados a efectos adversos, sobre todo en niños. De hecho, evitar el uso de estos medicamentos se toma como medida de calidad en el cuidado de los niños con OMS (Lannon et al., 20I I: er490; Patel et al., 2008: 490).

No se recomienda, por tanto, el uso de glucocorticoides orales en el tratamiento de la OMS en niños. El riesgo de efectos adversos supera su potencial beneficio a corto plazo (Rosenfeld et al., 20I6: SI-S4I; Principi et al., 20I6: 4I 5-423; O'Connor et al., 20I6: 2 I 5225).

\section{- Glucocorticoides intranasales}

$\mathrm{Al}$ igual que en el caso de los glucocorticoides orales, varias asociaciones médicas desaconsejan el uso de glucocorticoides nasales para el tratamiento de la OMS (American Academy of Family Phisicians et al., 2004: I 4I 2-I 429; NICE, 2008).

Estudios posteriores han demostrado que en niños de 4 a I I años tratados con mometasona nasal o placebo no hubo diferencia en la resolución del derrame o pérdida de la audición más allá de los tres meses (Williamson et al., 2009: I-I44). Pero sí hubo una desventaja económica en el grupo tratado con mometasona, considerando la alta tasa de resolución espontánea en el grupo de placebo.

Los esteroides vía tópica (intranasal) tienen menos efectos secundarios, especialmente 
cuando se compara con la administración sistémica, pero entre el $7 \%$ y el $22 \%$ de los pacientes del grupo de estudio experimentaron efectos secundarios menores (Simpson et al., 2007).

Es posible que a corto plazo haya un beneficio de la administración de los esteroides vía tópica intranasal en niños con hipertrofia de las adenoides, aunque el efecto es pequeño y la dosificación, en un estudio que lo apoya, fue mayor de lo recomendable (Bhargava y Chakravarti, 20I4: 766-770; Cengel y Akyol, 2006: 639-645; El-Anwar et al., 201 5: 298-301).

Asimismo, en una revisión sistemática Cochrane de 20 I I con diversos estudios sobre los glucocorticoides sistémicos y tópicos nasales para el tratamiento de la OMS en niños, se encontró que los glucocorticoides intranasales no fueron útiles en la resolución de la OMS, ni para mejorar la audición a corto plazo (Simpson et al., 20I I).

Tampoco se evaluó la capacidad de resolución a largo plazo, ni el desarrollo del habla. La no utilización de los glucocorticoides intranasales (a menos que haya causa justificada) igualmente es una medida de calidad en el cuidado de los niños con OMS (Lannon et al., 20I I: eI490; Patel et al., 2008: 490).

Con los datos disponibles en la actualidad no es posible confirmar el papel de la rinitis alérgica en la etiología de la OMS. También se ha especulado mucho sobre la relación entre la alergia en general y la OMS, sin que a día de hoy se haya llegado a ninguna conclusión.

No se han llevado a cabo estudios prospectivos en niños con OMS que examinen los efectos de la inmunoterapia en los alérgicos frente a otras opciones (American Academy of Family Phisicians et al., 2004: I4 I2-I429).

Por tanto, no se aconseja emplear los glucocorticoides intranasales en el tratamiento de la OMS (Klein y Pelton, 20I6; Rosenfeld et al., 20I6: SI-S4I; Principi et al., 20I6: 4I 5-423; O’Connor et al., 20I6: 2I 5-225).

\subsection{Antibióticos}

El fundamento para el tratamiento antibiótico de los niños con OMS surgió de la identificación de, al menos, un patógeno bacteriano en el líquido del oído medio en un tercio de estos pacientes. En la mayoría de los casos las bacterias cultivadas fueron las mismas que las que normalmente se encuentran en la otitis media aguda: Haemophilus influenzae, Moraxella catarrhalis y Streptococcus pneumoniae. Se sugirió por ello su tratamiento con los mismos fármacos recomendados para la OMA.

Hace tiempo que varios meta-análisis encontraron que los antibióticos mejoraban la eliminación de la OMS en el primer mes después del tratamiento, pero hubo recaídas frecuentes y ningún beneficio más allá del primer mes (Rosenfeld y Post, I992: 378; Williams et al., I993: I344).

Una revisión sistemática Cochrane en 2012 también llegó a la conclusión de que la evidencia no apoya el uso rutinario de antibióticos para niños con OMS (Van Zon et al., 20I2).

Este análisis se realizó sobre 23 estudios, con uso de antibióticos tanto a corto como a largo plazo en el tratamiento de la OMS, mostrando un pequeño beneficio para la resolución completa del derrame en algún momento de la evolución y en la complicación con OMA. Sin embargo, la terapia con antibióticos no tuvo ningún impacto significativo en la pérdida auditiva o la tasa de timpanostomía posterior y la inserción de tubos. Además, el efecto positivo se daba con tratamientos superiores al mes de duración. Los autores concluyeron que los antibióticos no deben utilizarse para tratar la OMS, dado que los pequeños beneficios no justifican los efectos adversos y el aumento de resistencias bacterianas que propicia, además de no tener ningún impacto en la pérdida auditiva o la futura cirugía.

Recientemente, en 2016, la Cochrane ha editado una actualización de estas recomendaciones que 
confirman la necesidad de valorar la moderada mejoría que los antibióticos pueden aportar frente a los efectos secundarios que producen y el aumento de resistencias bacterianas que propician (Venekamp et al., 20I 5, Venekamp et al., 20I6).

En conclusión, no se recomienda el uso de antibióticos de forma generalizada para el tratamiento de la OMS (Klein y Pelton, 20I6; Rosenfeld et al., 20I6: SI-S4I; Principi et al., 20I6: 4I 5-423; O'Connor et al., 20I6: 2I 5-225).

La no utilización de antibióticos es también un indicador de calidad en el cuidado de los niños con OMS (Lannon et al., 20I I: er 490; Patel et al., 2008: 490).

El uso inadecuado de los antibióticos puede afectar no sólo al individuo que los toma, sino también a su familia, a la comunidad y a la sociedad en su conjunto. Tratar un proceso no bacteriano con un antibiótico carece de utilidad y somete al paciente a riesgos innecesarios (reacciones alérgicas y otros efectos adversos). Además, el impacto ecológico sobre la flora respiratoria e intestinal es considerable, ya que el antibiótico eliminará la población mayoritaria de bacterias sensibles y favorecerá el crecimiento de la población bacteriana resistente y su posible diseminación posterior (MSSSI, 2006).

Estos hallazgos no deben impedir el uso de la terapia con antibióticos cuando haya enfermedades asociadas que se beneficiarían de su uso, tales como sinusitis bacteriana aguda o infección por estreptococo grupo A.

\subsection{Antihistamínicos y descongestionantes}

Los descongestionantes tienen como objetivo disminuir el edema e hinchazón de la mucosa, y la mejora de su función, asegurando la ventilación central y la reducción de fluido. Al igual que los esteroides, los antihistamínicos se indican para amortiguar la respuesta inflamatoria.

Diversas asociaciones médicas en 2004 y posteriormente las directrices NICE recomendaron que los antihistamínicos y descongestionantes no se deben utilizar en el tratamiento de la OMS en niños (American Academy of Family Phisicians et al., 2004: I 4 I 2-I 429; NICE, 2008).

La mejor evidencia en este sentido proviene de una revisión Cochrane de 2007 que incluyó I 6 ensayos clínicos con I 5 I 6 niños tratados con estos fármacos, solos o en combinación, cuyos resultados no mostraron ningún beneficio en la variable principal (persistencia de la OMS al cabo de un mes). Tampoco se demostró que se redujeran las recurrencias. Por el contrario, sí aumentaron los efectos adversos en comparación con el placebo (Griffin et al., 2007).

Esto se confirmó en una revisión sistemática posterior sobre la evaluación de los antihistamínicos y/o descongestivos para el tratamiento de la OMS, que concluyó que no había beneficio ni a corto (<I mes), ni a largo plazo (>3 meses), en la resolución de OMS. Ni se redujo la duración de las complicaciones, ni se impidió la OMA (Griffin y Flynn, 20II).

Por otra parte, no se encontró evidencia de efectos beneficiosos sobre la audición, aunque puede haber algún beneficio en términos de mejora de la sintomatología de alergia nasal y ocular.

Los efectos adversos de antihistamínicos y descongestionantes en niños también tienden a favorecer al grupo placebo sobre el grupo de tratamiento en varios estudios. El tratamiento con antihistamínicos y/o descongestivos se asoció con un aumento del riesgo de efectos secundarios en el I $7 \%$ de casos, frente al $6 \%$ entre los que recibieron placebo. Por ello, no se recomienda utilizar estos fármacos en el tratamiento de la OMS. No existe evidencia de su beneficio y sí del riesgo de posibles efectos adversos con su uso (Griffin et al., 2007; Griffin y Flynn, 20I I; Klein y Pelton, 20I6). Incluso en los niños con rinitis alérgica y OMS, estos medicamentos no son beneficiosos para esta última (Rosa-Olivares et al., 20I 5: 480-486). 


\subsection{Inhibidores de leucotrienos}

Estudios previos no demostraron que el montelukast sea eficaz en el aclaramiento de la secreción del oído medio (Schoem et al., 20ıо: 434-437), sin embargo, un estudio posterior en el uso de inhibidores de los leucotrienos, con o sin antihistamínico, demostró por otoscopia una mejoría estadísticamente significativa utilizando ambas terapias. No obstante, esta mejora no era significativa en las timpanometrías bilaterales (Ertugay et al., 2013: I266-I272).

\subsection{Mucolíticos}

La evidencia del posible beneficio de los mucolíticos en la OMS es muy limitada. La información disponible recomienda no usarlos (Klein y Pelton, 20I6; Rosenfeld et al., 20I6: SI$S_{4 I}$; Principi et al., 2016: 4I 5-423; O'Connor et al., 2016: 2I 5-225).

\subsection{Autoinsuflación}

La autoinsuflación se refiere al proceso de apertura de la trompa de Eustaquio, elevando la presión intranasal (por ejemplo, mediante la espiración forzada con la boca y la nariz cerrada, hinchar un globo a través de cada orificio nasal o el uso de un globo nasal manufacturado a propósito o algún otro aparato similar) (Perera et al., 2013; Williamson et al., 20I 5: 96I-969; Banigo et al., 2016: 59-65).

La autoinsuflación en la espera vigilante podría ser beneficiosa si el niño es capaz de realizar la técnica. Los estudios disponibles son controvertidos, de forma que se pueden encontrar revisiones o guías en las que no se recomienda su uso (Rovers et al., 2004: 465473 ), otras en las que con una evidencia de bajo grado se afirma que podría ser beneficiosa en algunos pacientes (SIGN, 2003) y otras revisiones más recientes en las que concluyen que es mejor utilizarla mientras se espera la resolución espontánea de la OMS, debido a la ausencia de efectos adversos (Perera et al., 2013;
Principi et al., 2016: 4I 5-423; Williamson, 20II: 0502; Williamson et al., 2015a: 96I-969).

En una revisión sistemática Cochrane de tres estudios, la autoinsuflación con un globo nasal fabricado a propósito disminuyó la secreción del oído medio según criterios timpanométricos y audiométricos, en un plazo de dos semanas a tres meses, comparándolo con no tratamiento (Perera et al., 2013).

No se observaron efectos adversos con la autoinsuflación. Sin embargo, algunos niños pueden tener dificultades para llevarla a cabo y esto puede limitar su aplicación en niños pequeños (Williamson, 201 I: 0502; Haggard, I999: I I 78). De hecho, en un ensayo, el I $2 \%$ de los niños (de 3 a I 2 años) se mostraron incapaces de usar el globo (Blanshard et al., I993: I88).

Estudios más recientes sí apoyan su utilización porque mejora varios aspectos clínicos y sintomatológicos, así como la calidad de vida de los niños con OMS (Bidarian, 2016: 65; Alper, 2016: 255; Williamson, 2011: 0502; Williamson et al., 20I 5 b: I-I 50). Además, puede reducir la necesidad de poner tubos de ventilación para el tratamiento definitivo (Banigo et al., 20I6: 5965).

En conclusión, la autoinsuflación podría ser un tratamiento útil para la OMS. Sin embargo, es difícil de realizar por niños pequeños que justamente son el grupo de edad en el que la OMS puede ser más perjudicial. Por otra parte, no se ha determinado aún el dispositivo más eficaz, que permita el mayor grado de cumplimiento.

\subsection{Tratamiento antirreflujo gastroesofágico}

Este enfoque se basa en el hecho de que se encuentran pepsina y pepsinógeno en la cavidad del oído medio de pacientes con OMS, que tal vez pueden derivar de un reflujo laringofaríngeo, indicando que éste se asocia con la patogénesis de la OMS en niños (Luo et al., 20I 5: I 252I 255 ). 
Hay algún trabajo que recomienda el tratamiento del reflujo gastroesofágico para la mejora de la otitis secretora (McCoul et al., 20II: 35-4I), aunque una revisión sistemática más reciente no confirmó su utilidad (Miura et al., 2012: 345-352).

La prevalencia de la enfermedad por reflujo gastroesofágico en niños con otitis media crónica con secreción y con otitis media aguda recurrente puede ser mayor que la prevalencia global para el resto de niños y la presencia de pepsina/pepsinógeno en el oído medio puede estar relacionada con el reflujo fisiológico, sin embargo, la relación de causa-efecto entre la pepsina/pepsinógeno en el oído medio y la OMS no está demostrada.

En conclusión, el tratamiento antirreflujo para la OMS no puede ser recomendado basándose en las investigaciones existentes.

\subsection{Terapias complementarias y alternativas}

\section{- Probióticos e interleukinas}

Hay estudios con probióticos para el tratamiento de la OMS que han tenido resultados prometedores, pero necesitan ser replicados antes de que este tratamiento pueda ser recomendado. En ensayos aleatorios, los niños con OMS prolongada que recibieron dos veces al día, por vía intranasal, Streptococcus sanguinis y otros alfa streptococos (mitis, oralis), que interfieren el crecimiento de otras bacterias patógenas, o Lactobacillus rhamnosus, tenían mayores tasas de curación clínica y menores recurrencias en comparación con los que recibieron placebo intranasal. No se identificaron efectos adversos (Skovbjerg et al., 2009: 92; Roos et al., 200I: I-4; Di Pierro et al., 20I2: 99I-997).

Esta área de investigación tiene su base en la existencia de biofilms bacterianos en el oído medio y, sobre todo, en las adenoides que podrían tener relación con la OMS y la OMA, actuando como reservorio de patógenos, lo que podría abrir nuevas opciones terapéuticas
(Tawfik et al., 2016; Van Hoecke et al., 2016; Davcheva-Chakar et al., 2015: 7I-76).

Nuevos enfoques para el tratamiento de esta enfermedad pasan también por el conocimiento y regulación de citoquinas inflamatorias, como la ILıo, que están elevadas en niños con OMS crónica (Zielnik y Stankiewicz, 2016: I04-I08).

\section{- Homeopatía}

Los pocos estudios publicados sobre los remedios homeopáticos para infecciones del oído medio u OMS tienen defectos en el diseño del estudio, incluyendo el tamaño pequeño de la muestra, la falta de asignación al azar o el cegamiento y la falta de validación del diagnóstico (Harrison et al., I999: I32; Jacobs et al., 200I: I77).

Recientemente, se ha publicado un artículo randomizado y doble ciego que concluye que el tratamiento homeopático no es efectivo (Pedrero et al., 20I 6: 217-223).

Además, no hay regímenes homeopáticos estandarizados para la otitis media y no hay datos sobre las dosis o planes adecuados.

\section{- Inmunomoduladores}

Otro medicamento empleado en la OMS, el $\mathrm{AM}_{3}$ (inmunoferón ${ }^{\circledR)}$ tampoco ha demostrado efectividad (Ortega et al., 2005: I-5), por lo que no se puede recomendar este tratamiento.

La Guía NICE (2008) no recomienda la homeopatía, la osteopatía craneal, la acupuntura, las modificaciones en la dieta (incluyendo probióticos), inmunoestimulantes, ni el masaje.

Las últimas revisiones no han cambiado esta no indicación (Principi et al., 20I 6: 4I 5-423) y sí han advertido de la posibilidad de efectos secundarios, sobre todo ligados al empleo de remedios herbales. Resumiendo, las guías de referencia de reconocidas asociaciones médicas 
no hacen ninguna recomendación respecto a terapias complementarias y alternativas para la OMS en base a la falta de pruebas suficientes (Klein y Pelton, 20I6; Rosenfeld et al., 2016: SI-S4I; Principi et al., 20I6: 4I 5-423).

\subsection{Vacunas}

Aunque es lógico pensar que las vacunas de la gripe y aquellas que cubren los patógenos habituales en la OMA pueden reducir de forma secundaria la incidencia de la OMS, que se origina por procesos infecciosos respiratorios o por otra patología otorrinolaringológica (Principi et al., 20I6: 4I 5-423), recientemente se ha publicado una revisión sistemática y meta-análisis sobre el efecto de la vacunación antineumocócica en la prevención de la OMS en la que se han identificado tres estudios que no demostraban ningún efecto beneficioso directo sobre la misma (El-Makhzangy et al., 20 I2: 2021-2026; Antolí-Candela et al., 2013).

\section{Tratamiento quirúrgico de la OMS infantil}

Se debe considerar el tratamiento quirúrgico de la OMS cuando ésta persiste durante más de tres meses. Esta conducta variará en los niños en situaciones de riesgo (Tabla I).

Además, hay que tener en cuenta que en ciertos niños puede evolucionar a la cronicidad con más probabilidad cuando se dan circunstancias como (Van Balen y de Melker, 2000: 605-6I I) la existencia de OMS en periodos estacionales con el inicio en verano o en otoño, pérdida auditiva mayor de $30 \mathrm{~dB}$ en el mejor oído, historia previa con drenajes transtimpánicos (DTT) y no estar adenoidectomizado.

La decisión respecto a la realización de cirugía se debe tomar consensuada entre el otorrinolaringólogo, los padres y el pediatra. En caso de que no haya consenso es mejor ampliar la información, dejar un tiempo para pensar y volver a tener otra visita en la consulta para retomar la decisión (Elwyn et al., 20I3: 207-2I2).

Entre los niños que llevan más de tres meses con OMS, se debe tener en cuenta si este tipo de tratamiento va a aportar o no beneficio. Para ello debemos hacer una prueba audiológica adecuada a la edad del niño antes de la cirugía. Si ésta muestra umbrales mejores o iguales a $20 \mathrm{~dB}$, se debe reevaluar cada tres meses hasta la completa resolución de la OMS. También se deben controlar con la misma periodicidad las alteraciones de la membrana timpánica (Heidemann et al., 2016: I 54-I63).

En caso de umbrales de más de $25 \mathrm{~dB}$ de media en las frecuencias de 500,1000, 2000 y $4000 \mathrm{~Hz}$ en el mejor oído, estaría indicada la cirugía. También sería adecuado, siempre que se pueda, hacer una valoración audiológica de inteligibilidad en la percepción del lenguaje.

En niños con hipoacusias menores de $25 \mathrm{~dB}$, se debe valorar la realización de la cirugía si éstos tienen retraso en el lenguaje o algún otro tipo de situación de riesgo.

A la hora de seleccionar qué tipo de cirugía se debe realizar, se tiene en cuenta la edad de los niños, tomando como referencia los cuatro años de edad (Gates et al., I987: I444-I45I; Boonacker et al., 20I4: I-I I 8; Mikals y Brigger, 2OI4: 95-IOI).

En los niños menores de cuatro años sólo está indicada la colocación de DTT, ya que no se ha encontrado evidencia científica de que la realización de adenoidectomía simultánea produzca mayor beneficio, salvo que exista indicación de ésta por alguna otra circunstancia.

En los niños de cuatro años o más, sí se ha encontrado un beneficio en la realización de una adenoidectomía de forma simultánea a la colocación de DTT con tasas de recurrencias de sólo el $7 \%$, en vez del $20 \%$ de los no adenoidectomizados. Por lo tanto, a partir de esta edad, se debe ofrecer la realización de adenoidectomía, si no se ha realizado antes por 
cualquier otra causa, a la vez que insertamos los DTT (Cervera et al., 2006: 59-65; Wallace et al., 20I4: 296-3II).

El beneficio de la adenoidectomía es reducir las recaídas, con independencia del tamaño de las adenoides o de si la OMS está relacionada con las bacterias a ese nivel formando biofilms (Nguyen et al., 2004: 863-866).

A cualquier edad, estaría indicada la colocación de DTT en las situaciones en que se aprecie un riesgo de producirse una alteración en la estructura de la membrana timpánica o que ésta ya se haya producido como una retracción, consecuencia de un gradiente de presión negativo en la caja del tímpano o una atelectasia, con objeto de evitar otras cirugías más extensas, secundarias a lo referido o primeros signos de colesteatoma.

La colocación de DTT no estaría indicada en los niños que presenten otitis media aguda sin coexistir con OMS crónica. Tampoco se ha encontrado beneficio de la adenoidectomía para prevenir las OMA de repetición.

\subsection{Complicaciones de la colocación de DTT}

Entre otras complicaciones posibles (Tabla 3), la más prevalente es la otorrea, que ocurre en el I $6 \%$ de los casos durante las cuatro primeras semanas y en un $26 \%$ a lo largo de todo el tiempo en el que se llevan los DTT (Vlastarakos et al., 2007: 385-39I; Kay et al., 200I: 374-380; Rakover et al., 2000: 4I-44).

La otorrea está relacionada con los biofilm que se producen alrededor del DTT (Idicula et al., 2016: I946-I95I). En caso de otorrea a través de DTT, sólo se deben recetar gotas antibióticas tópicas, sin toma de antibióticos por vía oral, salvo infecciones complicadas.

Las complicaciones de la adenoidectomía son poco frecuentes (De Luca et al., 20I5: 702- 7 I8). Entre ellas, el aumento del tiempo quirúrgico, el riesgo de sangrado postoperatorio, mayor disconfort en los 2-3 días posteriores
Tabla 3. Complicaciones en la colocación de drenajes transtimpánicos (DTT)

- Otorrea (16-26\%)

- Obstrucciones del DTT (7\%)

- Perforaciones residuales (2-3\%)

- Introducción en el oído medio (0,5\%)

- Colesteatomas residuales ( $<1 \%)$, aunque hay evidencia de su disminución al tratar las otitis medias secretoras con DTT

- Extrusiones prematuras de los DTT (44\%)

- Otro tipo de alteraciones de la membrana (timpanosclerosis, atrofias, etc.) no suelen tener repercusiones sobre la audición

Fuente: elaboración propia.

a la cirugía y, raramente, rinolalia abierta o disfunción tubárica.

No hay que olvidar que los niños precisan de seguimiento a largo plazo para asegurar que la audición se ha corregido y que la inteligibilidad en la percepción del lenguaje ha mejorado. Para ello, haremos las pruebas audiométricas necesarias. Por otro lado, hay que tener en cuenta que, tras la extrusión de los DTT, la reincidencia de una OMS, que puede llegar a precisar la colocación de otros nuevos, se estima entre el $20 \%$ y el $54 \%$ de los casos, según distintos autores.

Entre los beneficios de la colocación de DTT destacan la mejora de la calidad de vida de los niños y de sus cuidadores a corto plazo, la reducción de la prevalencia de OMS en un $32 \%$ en el primer año y mejora de los niveles de audición (Browning et al., 2010), así como la mejora del habla y del lenguaje, fundamentalmente en niños con factores de riesgo (Tabla I) (Rosenfeld et al., 20I I: I90I95). 


\section{Información y orientaciones para la familia}

Es importante informar a los padres del niño diagnosticado de otitis media secretora con el fin de mejorar el proceso de toma de decisiones compartido con el profesional. Esta tarea puede ser abordada entregando una lista de preguntas frecuentes, que debe completarse con un intercambio de información accesible para la familia y que responda a sus necesidades. La información aportada por la familia es muy valiosa, pero no puede ser el único método para identificar si existe pérdida auditiva o no.

Los aspectos más importantes a tratar en el proceso de información a las familias son los factores predisponentes, la historia natural de la enfermedad, el riesgo de daño al oído medio y las opciones existentes para minimizar los efectos de la otitis secretora (Rosenfeld et al.,

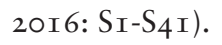

\subsection{Factores predisponentes de OMS}

Entre los factores que provocan la aparición de la OMS (Casselbrant y Mandel, 2003), destaca la edad por estar en relación directa con la angulación de la trompa de Eustaquio. Otros factores son el tabaquismo pasivo, sexo masculino y la asistencia a guardería (Todberg et al., 20I4: eIII732). Existe también un componente familiar.

En los niños menores de I 8 meses es importante limitar el uso de chupetes porque con ello se puede reducir la incidencia de otitis media aguda en un $30 \% \mathrm{y}$, en consecuencia, la de la otitis media secretora que de forma rutinaria sucede a la primera.

El riesgo disminuye sustancialmente si el niño ha sido alimentado con leche materna, protegiendo más tiempo contra la OMS cuanto más prolongada sea dicha lactancia. Existen numerosos estudios que demuestran que la lactancia materna disminuye el riesgo de padecer
OMS por la transmisión de anticuerpos desde la madre al lactante y por reducir las alergias ambientales (Schilder et al., 2004: 29-36). Una buena higiene de las manos también es una medida beneficiosa.

\subsection{Historia natural de la OMS}

La OMS es un proceso que evoluciona hacia la curación espontánea en la mayoría de los casos, pero depende de la causa y el tiempo transcurrido desde su instauración. En el $75 \%$ de los niños, la OMS se ha resuelto en tres meses cuando su causa ha sido una otitis media aguda previa. Si la OMS es espontánea y se desconoce cuándo apareció, la tasa de resolución a los tres meses baja al $56 \%$.

Es menos probable su resolución en los niños en los que aparece en los meses de verano u otoño, los que presentan umbrales audiométricos peores de $30 \mathrm{~dB}$ y/o una historia previa de colocación de drenajes transtimpánicos (Van Balen y de Melker, 2000: 605-6II).

\subsection{Riesgo de daño al oído medio}

Aunque poco frecuente, hay que tener en cuenta el riesgo de que se produzcan secuelas como retracción o atelectasia de la membrana timpánica, lesiones de los huesecillos timpánicos, formación de colesteatoma y perforación timpánica.

\subsection{Cómo minimizar los efectos de la otitis secretora}

Existen diferentes opciones para minimizar los efectos de la otitis media secretora en términos de hipoacusia, desarrollo del habla y del lenguaje, así como sobre el aprovechamiento escolar. Se debe instruir sobre las estrategias para optimizar la escucha y el aprendizaje mientras la otitis se resuelve (Tabla 4 ). Se debe hablar al niño situándose cerca y frente a él, con una clara pero natural pronunciación. También se puede recurrir a estrategias adicionales de 
comunicación que pueden aumentar la atención del niño, reduciendo el ruido ambiente si es posible y repitiendo o aclarando la información que se le intenta transmitir. Se debe colocar al niño en sitios preferentes en la clase, en las primeras filas y con el mejor oído orientado al docente (Roberts et al., 2004: e238-e248; Jáudenes et al., 2006; Jáudenes y Patiño, 2007).

Los padres deben saber que los medicamentos carecen de utilidad en el tratamiento de la OMS (Van Zon et al., 20I2). Y, a pesar de la popularidad de las terapias alternativas y complementarias, no existe evidencia de que aporten beneficios en la otitis media secretora (Berkman et al., 2013).

\section{Recomendaciones CODEPEH 2016}

I. En el diagnóstico de la otitis media secretora infantil, se debe documentar la presencia de contenido seromucoso en la caja timpánica por medio de la otoscopia neumática, la timpanometría o la otomicroscopia.

2. Ante una otitis media secretora en un niño que no presenta factores de riesgo, se recomienda una espera vigilada de tres meses antes de plantear una actuación terapéutica. La autoinsuflación es una medida que puede ayudar durante este tiempo.

\section{Tabla 4. Pautas y estrategias de comunicación con niños con pérdidas auditivas}

Llamar su atención

- Antes de empezar a hablar, llamar su atención y esperar a que esté mirando para empezar a hablar

- Si hay más de una persona o se trata de una conversación en grupo, respetar los turnos entre los interlocutores e indicar quién habla cada vez

Hablar de frente

- Situarse siempre a la altura del niño

- Hablar de frente. No dar la espalda

- Hablar sin ningún objeto, caramelo o chicle en la boca y sin taparla con las manos mientras se habla

- Evitar que la luz le deslumbre

Hablar con naturalidad

- Hablar con naturalidad, vocalizando pero sin exagerar, con un ritmo tranquilo. Ni demasiado despacio, ni demasiado deprisa

- Hablar sin gritar, en un tono de voz normal

- Hablar con frases completas, contextualizadas y usando palabras conocidas

Hablar con tranquilidad

- Repetir el mensaje, asegurando que ha sido comprendido, con frases más sencillas

- Facilitar la comprensión con dibujos, palabras escritas o gestos naturales

- Contestar a sus preguntas. Escucharle siempre. Darle tiempo para hablar y para responder

- No interrumpir la interacción comunicativa aunque se produzcan errores en el lenguaje

Otras estrategias

- Estar atentos a sus intereses e intenciones comunicativas, a los objetos y actividades que le gustan, observando sus reacciones, su actitud en respuesta al estímulo y sus producciones de habla en esos contextos

- Evitar corregirle directa y frecuentemente si algo lo pronuncia mal o confunde los términos. De forma natural, repetir la palabra que ha equivocado en nuevas frases que le aporten más información. Es importante ofrecer modelos de lenguaje correctos

- Controlar ambiente: estancias bien iluminadas y poco ruidosas, bajando el volumen de la televisión, reproductores de música, etc., mientras se habla

- Situarle donde pueda ver al profesor y a la mayoría de compañeros, ya sea en un círculo, en las primeras filas... dependiendo de la actividad del aula y de los juegos

Fuente: revisado y actualizado de Jáudenes, C y Patiño, I., 2007. 
3. Todo niño que presenta factores de riesgo debe ser examinado para descartar la existencia de una otitis media secretora, tanto en el momento del diagnóstico del factor de riesgo como a los I2-I 8 meses de edad.

4. No se recomienda el cribado de la otitis media secretora en los niños sin presencia de factores de riesgo u otros síntomas atribuibles a la misma como hipoacusia, problemas de equilibrio, bajo rendimiento escolar, problemas de conducta o síntomas otológicos.

5. En el caso de que se atribuya a una otitis media secretora el fallo en el cribado neonatal de la hipoacusia, se recomienda el seguimiento del niño hasta la completa resolución de la misma y la realización de una prueba audiológica que descarte una hipoacusia neurosensorial subyacente.

6. Se debe realizar una prueba audiológica apropiada a la edad del niño si la otitis media secretora se prolonga más de tres meses. En los niños con factores de riesgo debe hacerse en el momento del diagnóstico.

7. Se debe determinar si en un niño con otitis media secretora existen otros factores sensoriales, físicos, cognitivos o conductuales concomitantes que le sitúen en riesgo de presentar alteraciones o retrasos en el desarrollo del lenguaje y/o del habla, así como en sus aprendizajes.

8. Se debe informar a la familia de los factores predisponentes y de la historia natural de la otitis media secretora, incluyendo una advertencia sobre otras secuelas que se pueden presentar y el posible desarrollo de otitis medias agudas secundarias, además de la necesidad de hacer un seguimiento de la evolución del niño.

9. Si se indica un tratamiento quirúrgico para la otitis media secretora:

a. en el caso de niños menores de cuatro años, se recomienda la colocación de tubos de drenaje transtimpánico, sin adenoidectomía, a no ser que existan síntomas de hipertrofia adenoidea.

b. en niños mayores de cuatro años, se recomienda la colocación de tubos de drenaje y adenoidectomía.

Io. En el tratamiento de la otitis media secretora no se aconseja el uso de esteroides sistémicos o intranasales, ni de antibióticos, antihistamínicos, descongestivos u otros tratamientos para la alergia, tratamiento antirreflujo, inmunomoduladores y probióticos. Tampoco se recomienda el uso de homeopatía u otras terapias alternativas. 
Abbott, P. et al. (20I4): "The effect and acceptability of tympanometry and pneumatic otoscopy in general practitioner diagnosis and management of childhood ear disease". BMC Fam Pract, I5: I 8I.

Alper, C. M. (2016): "Efficacy of nasal balloon autoinflation for otitis media with effusion". J Pediatr, I68: 255.

American Academy of Family Physicians et al. (2004): "Otitis media with effusion". Pediatrics, II3: I4 I 2-I429.

American Academy of Pediatrics JCoIH (2007): "Year 2007 position statement: Principles and guidelines for early hearing detection and intervention programs”. Pediatrics, I 20 (4): 898-92I.

Antolí-Candela, J. et al. (2013): Consenso para el diagnóstico y tratamiento de la otitis seromucosa infantil. Madrid: Asociación Madrileña de Otorrinolaringología (AMORL).

Baldwin, M. (2006): "Choice of probe tone and classification of trace patterns in tympanometry undertaken in early infancy". Int J Audiol, 45 (7): 4I7-427.

Banigo, A. et al. (2016): "Does the EarPopper(®) device improve hearing outcomes in children with persistent otitis media with effusion? A randomised single-blinded controlled trial”. Clin Otolaryngol, 4I: 59-65.

Berkman, N.D. et al. (2013): Otitis media with effusion: comparative effectiveness of treatments. Comparative effectiveness review $\mathrm{N}^{\circ}$ IOI. Rockville, M. D: Agency for Healthcare Research and Quality (AHRQ).

Bhargava, R. y Chakravarti, A. (20I4): “A doubleblind randomized placebo-controlled trial of topical intranasal mometasone furoate nasal spray in children of adenoidal hypertrophy with otitis media with effusion". Am J Otolaryngol, 35: 766-770.

Bhutta, M. F. (20I4): "Epidemiology and pathogenesis of otitis media: construction of a phenotype landscape". Audiol Neurootol, I9: 210-223.

Bidarian, A. (2016): “Autoinflation reduces middle ear effusion in children with otitis media with effusion”. Evid Based Med, 21: 65.

Blanshard, J. D. et al. (I993): "Conservative treatment of otitis media with effusion by autoinflation of the middle ear". Clin Otolaryngol Allied Sci, I8: I88.

Boonacker, C. W. et al. (2OI4): “Adenoidectomy with or without grommets for children with otitis media: an individual patient data metaanalysis". Health Technol Assess, I 8 (5): I-I I 8.

Boone, R. T. et al. (2005): "Failed newborn hearing screens as presentation for otitis media with effusion in the newborn population". Int J Pediatr Otorhinolaryngol, 69:393-397.

Boudewyns, A. et al. (20I I): "Otitis media with effusion: an underestimated cause of hearing loss in infants". Otol Neurotol, 32: 799-804.

Brouwer, C. N. et al. (2005): "Health-related quality of life in children with otitis media". Int J Pediatr Otorhinolaryngol, 69: I03 I-IO4I.

Browning, G. G. et al. (2010): “Grommets (ventilation tubes) for hearing loss associated with otitis media with effusion in children". Cochrane Database Syst Rev, Io: CDoor 801 .

Calderon, R. y Naidu, S. (I999): “Further support for the benefits of early identification and intervention for children with hearing loss". Volta Rev, IоO: 53-84.

Casselbrant, M. L. y Mandel, E. M. (2003): "Epidemiology", en Rosenfeld, R. M. y Bluestone, C. D. (eds.): Evidence-Based Otitis Media. Hamilton, Canada: BC Decker Inc.

Cengel, S. y Akyol, M. U. (2006): “The role of topical nasal steroids in the treatment of children with otitis media with effusion and/or adenoid hypertrophy". Int J Pediatr Otorhinolaryngol, 70: 639-645. 
Cervera, J. et al. (2006): "Indications for tonsillectomy and adenoidectomy: consensus document by the Spanish Society of ORL and the Spanish Society of Pediatrics". Acta Otorrinolaringol Esp, 57 (2): 59-65.

Davcheva-Chakar, M. et al. (2015): “Adenoid vegetations - reservoir of bacteria for chronic otitis media with effusion and chronic rhinosinusitis". Pril (Makedon Akad Nauk Umet Odd Med Nauki), 36: 7I-76.

De Luca Canto, G. et al. (2015): "Adenotonsillectomy complications: A metaanalysis”. Pediatrics, I36 (4): 702-7 I 8.

Di Pierro, F. et al. (20I2): "Preliminary pediatric clinical evaluation of the oral probiotic Streptococcus salivarius $\mathrm{K}_{\mathrm{I} 2}$ in preventing recurrent pharyngitis and/or tonsillitis caused by Streptococcus pyogenes and recurrent acute otitis media”. International Journal of General Medicine, 5: 991-997.

El-Anwar, M. W. et al. (2OI 5): "The efficacy of nasal steroids in treatment of otitis media with effusion: a comparative study". Int Arch Otorbinolaryngol, I9: 298-301.

El-Makhzangy, A. M. et al. (2012): "Can vaccination against pneumococci prevent otitis media with effusion?". Eur Arch Otorhinolaryngol, 269: 202I-2026.

Elwyn, G. et al. (2013): "Option Grids: shared decision making made easier". Patient Educ Couns, 90 (2): 207-2I2.

Ertugay, C. K. et al. (20I3): "Effect of combination of montelukast and levocetirizine on otitis media with effusion: a prospective, placebo-controlled trial". Acta Otolaryngol, I33: I266-I272.

Gates, G. A. et al. (I987): "Effectiveness of adenoidectomy and tympanostomy tubes in the treatment of chronic otitis media with effusion". N Engl J Med, 3 I 7 (23): I444-I 45 I.

Griffin, G. H. y Flynn, C. A. (20II):

"Antihistamines and/or decongestants for otitis media with effusion (OME) in children". Cochrane Database Syst Rev, 9: CDoo3423.

Griffin, G. H. et al. (2007): Antibistamínicos y descongestivos para la otitis media exudativa (OME) en niños (Revisión Cochrane traducida) (en línea). <http://www.bibliotecacochrane. com/BCPGetDocument.asp? SessionID=\% 20 I I $843047 \&$ DocumentID=CDo03423>, acceso I de junio de 2017.

Group MRCM-cOMS (2009): “Air-conduction estimated from tympanometry (ACET) I: relationship to measured hearing in OME". Int J Pediatr Otorhinolaryngol, 73 (I): 2I-42.

Haggard, M. (I999): “Commentary: plausible candidates for treatment of glue ear-is one issue really three?". BMJ, 3 I8: I I78.

Harrison, H. et al. (I999): “A randomized comparison of homoeopathic and standard care for the treatment of glue ear in children". Complement Ther Med, 7: I32.

Heidemann, C. H. et al. (2016): "Danish guidelines on management of otitis media in preschool children”. Int J Pediatr Otorhinolaryngol, 87: I 54 - 163 .

Idicula, W. K. et al. (2016): "Identification of biofilms in post-tympanostomy tube otorrhea". Laryngoscope, I26 (8): I946-I95I.

Iino, Y. et al. (1999): "Efficacy of tympanostomy tube insertion for otitis media with effusion in children with Down syndrome". Int J Pediatr Otorhinolaryngol, 49: I43-I49.

Jacobs, J. et al. (200I): "Homeopathic treatment of acute otitis media in children: a preliminary randomized placebo-controlled trial". Pediatr Infect Dis J, 20: I77.

Jáudenes, C. y Patiño, I. (2007): Dossier divulgativo para familias con hijoslas con discapacidad auditiva. Información básica para el acceso temprano a la lengua oral. Madrid: Confederación Española de Familias de Personas Sordas-FIAPAS.

Jáudenes, C. et al. (2006): Dossier de prevención y atención precoz de los problemas auditivos en edad escolar. Madrid: Confederación Española de Familias de Personas Sordas-FIAPAS.

Jáudenes, C. (2004): “Signos de alerta en el comportamiento del bebé y del niño”, en Jáudenes, C. et al. (dir.): Manual básico de formación especializada sobre discapacidad auditiva. Madrid: Confederación Española de Familias de Personas Sordas-FIAPAS. 
Jerger, J. (I970): “Clinical experience with impedance audiometry". Arch Otolaryngol, 92 (4): 3II-324.

Jung T. T. K. et al. (2013): "Panel 8: complications and sequelae”. Otolaryngol Head Neck Surg, I 48 (4): EI22-EI43.

Kaleida, P. H. y Stool S. E. (I992): “Assessment of otoscopists' accuracy regarding middle-ear effusion. Otoscopic validation”. Am J Dis Child, I46 (4): 433-435.

Karkanevatos, A. y Lesser, T. H. (I998): “Grommet insertion in children: a survey of parental perceptions". J Laryngol Otol, I I 2: 732-74I.

Karma, P. H. et al. ( I989): “Otoscopic diagnosis of middle ear effusion in acute and non-acute otitis media. I. The value of different otoscopic findings". Int J Pediatr Otorhinolaryngol, I7 (I): 37-49.

Kay, D. J. et al. (200I): "Meta-analysis of tympanostomy tube sequelae". Otolaryngol Head Neck Surg, 24 (4): 374-380.

Khavarghazalani, B. et al. (2016): “Auditory processing abilities in children with chronic otitis media with effusion". Acta OtoLaryngologica, I 36: 456-459.

Klein, J. O. y Pelton, S. (20I6): Otitis media with effusion (serous otitis media) in children: Management (en línea). <https://www. uptodate.com/contents/otitis-media-witheffusion-serous-otitis-media-in-childrenmanagement? source=see_link $>$, acceso 2 de junio de 2017.

Lannon, C. et al. (20II): "Quality measures for the care of children with otitis media with effusion". Pediatrics, I27: eI490.

Lee, D. H. (20I0): "How to improve the accuracy of diagnosing otitis media with effusion in a pediatric population". Int J Pediatr Otorhinolaryngol, 74 (2): I 5 I-I 53.

Luo, H. et al. (201 5): "The expression and clinical significance of pepsin and pepsinogen in patients with otitis media with effusion". Lin Chung Er Bi Yan Hou Tou Jing Wai Ke Za Zhi, 29: I252-I 255 .
Macknin, M. L. y Jones, P. K. (I985): “Oral dexamethasone for treatment of persistent middle ear effusion". Pediatrics, 75: 329.

Mandel, E. M. et al. (2008): "The incidence, prevalence and burden of OM in unselected children aged I-8 years followed by weekly otoscopy through the 'common cold' season". Int J Pediatr Otorhinolaryngol, 72: 49I-499.

Marchisio, P. et al. (2008): "Otitis media with effusion and hearing loss in children with Cornelia de Lange Syndrome”. Am J Hum Genet Part A, I46A: 426-432.

Maris, M. et al. (20I4): “A cross-sectional analysis of otitis media with effusion in children with Down syndrome". Eur J Pediatr, I73: I3 I9I325.

McCoul, E. D. et al. (2OI I): “A prospective study of the effect of gastroesophageal reflux disease treatment on children with otitis media”. Arch Otolaryngol Head Neck Surg, I37: 35-4I.

Mena, E. A. et al. (2016): "High frequency tympanometry $(\mathrm{I} 000 \mathrm{~Hz})$ in young infants and its comparison with otoacoustic emissions, otomicroscopy and $226 \mathrm{~Hz}$ tympanometry". Acta Otorrinolaringol Esp, 67 (6): 306-3 I 4.

Mikals, S. J. y Brigger, M. T. (2OI4): "Adenoidectomy as an adjuvant to primary tympanostomy tube placement: a systematic review and meta-analysis”. JAMA Otolaryngol Head Neck Sur, I40 (2): 95-IOI.

Miura, M. S. et al. (2012): “Association between otitis media and gastroesophageal reflux: a systematic review". Otolaryngol Head Neck Surg, I46: 345-352.

MSSSI (2006): Campaña para el uso racional de los antibióticos. Ministerio de Sanidad y Consumo (en línea). <http://www.antibioticos. msssi.gob.es/PDF/antibioticos.pdf $>$, acceso 6 de septiembre de 2016.

NICE (2008): Surgical management of otitis media with effusion in children (en línea). <http://www.nice.org.uk/nicemedia/pdf/ CG6oNICEguideline.pdf>, acceso 20 de junio de 2016. 
Nguyen, L. H. et al. (2004): “Adenoidectomy: selection criteria for surgical cases of otitis media”. Laryngoscope, I I 4 (5): 863-866.

Nozza, R. J. et al. (I992): “Towards the validation of aural acoustic immittance measures for diagnosis of middle ear effusion in children”. Ear Hear, I3 (6): 442-453.

Núñez F. et al. (20I6): "Recomendaciones CODEPEH 20I4: detección precoz de la hipoacusia diferida, diagnóstico audiológico y adaptación audioprotésica y atención temprana”. Acta Otorrinolaringol Esp, 67 (I): $45-53$.

Núñez, et al. (2014): "Sorderas diferidas y sobrevenidas en la infancia: Recomendaciones CODEPEH 20I4". Revista FIAPAS, I 5 , Separata (documento íntegro).

O’Connor, S. S. et al. (20I6): "Plain language summary: otitis media with effusion". Otolaryngol Head Neck Surg, I 54: 21 5-225.

Ortega, P. et al. (2005): "The effect of $\mathrm{AM}_{3}$ in the resolution of otitis media with effusion (OME) in pediatric patients". Acta Otorrinolaringol Esp, 56: I-5.

Paradise, J. L. et al. (I997): "Otitis media in 2253 Pittsburgh-area infants: prevalence and risk factors during the first two years of life". Pediatrics, 99: 3 I 8-333.

Patel, M. M. et al. (2008): “Assessment of acute otitis externa and otitis media with effusion performance measures in otolaryngology practices”. Otolaryngol Head Neck Surg, I39: 490.

Pedrero, M. F. et al. (2016): "Hospital clinical trial: homeopathy (Agraphis nutans ${ }_{5} \mathrm{CH}$, Thuya occidentalis ${ }_{5} \mathrm{CH}$, Kalium muriaticum ${ }_{9} \mathrm{CH}$ and Arsenicum iodatum $9 \mathrm{CH}$ ) as adjuvant, in children with otitis media with effusion". Int J Pediatr Otorhinolaryngol, 88: 2 I7-223.

Perera, R. et al. (2013): "Autoinflation for hearing loss associated with otitis media with effusion". Cochrane Database Syst Rev, 5: CDoo628 5.

Ponduri, S. et al. (2009): “The management of otitis media with early routine insertion of grommets in children with cleft palate: a systematic review". Cleft Palate Craniofac J, 46: $30-38$.

Principi, N. et al. (2016): "Otitis media with effusion: benefits and harms of strategies in use for treatment and prevention”. Expert Rev Anti Infect Ther, I4: 4I 5-423.

Qureishi, A. et al. (20I4): "Update on otitis media: prevention and treatment". Infect Drug Resist, 7: I 5-24.

Rakover, Y. et al. (2000): "Comparison of the incidence of cholesteatoma surgery before and after using ventilation tubes for secretory otitis media”. Int J Pediatr Otorhinolaryngol, 56 (I): $4 \mathrm{I}-44$.

Roberts, J. E. et al. (2004): "Otitis media and speech and language: a meta-analysis of prospective studies". Pediatrics, I I 3 : e238-e248.

Roberts, J. E. et al. (2000): "Otitis media in childhood in relation to preschool language and school readiness skills among black children". Pediatrics, I06: 725-735.

Roos, K. et al. (200I): "Effect of recolonisation with 'interfering' alpha streptococcion recurrences of acute and secretory otitis media in children: randomised placebo controlled trial". BMJ, 322: I-4.

Rosa-Olivares, J. et al. (20I 5): "Otitis media: to treat, to refer, to do nothing: a review for the practitioner". Pediatr Rev, 36: 480-486.

Rosenfeld, R. M. et al. (20I6): "Clinical practice guideline: Otitis media with effusion (Update)”. Otolaryngol Head Neck Surg, I 54 (IS): SI-S4I.

Rosenfeld, R. M. et al. (2013): "Clinical practice guideline: tympanostomy tubes in children". Otolaryngol Head Neck Surg, I49: SI-S35.

Rosenfeld, R. M. et al. (20I I): "Tympanostomytubeoutcomes in children atrisk and not at-risk for developmental delays". Int J Pediatr Otorhinolaryngol, 75 (2): 190I95.

Rosenfeld, R. M. et al. (2004): “Clinical practice guideline: otitis media with effusion". Otolaryngol Head Neck Surg, I30: S95-Si I 8. 
Rosenfeld, R. M. y Kay D. (2003): “Natural history of untreated otitis media". Laryngoscope, II3: I645-1657.

Rosenfeld, R. M. et al. (2000): "Impact of tympanostomy tubes on child quality of life". Arch Otolaryngol Head Neck Surg, I 26: 585 592.

Rosenfeld, R. M. y Post, J. C. (I992): “Metaanalysis of antibiotics for the treatment of otitis media with effusion". Otolaryngol Head Neck Surg, 106: 378 .

Rovers, M. M. et al. (2004): "Otitis media". Lancet, 363: 465-473.

Ruben, R. J. (20II): “Otitis media: the application of personalized medicine". Otolaryngol Head Neck Surg, I 45: 707-7I 2.

Ruben, R. (2003): "Host susceptibility to otitis media sequelae”, en Rosenfeld, R. M. y Bluestone, C. D. (eds.): Evidence-Based Otitis Media. 2nd ed. Hamilton, Canada: BC Decker Inc.

Schilder, A. G. M. et al. (2004): "International perspectives on management of acute otitis media: a qualitative review". Int J Pediatr Otorhinolaryngol, 68: 29-36.

Schoem, S. R. et al. (2010): “A prospective, randomized, placebo-controlled, double-blind study of montelukast's effect on persistent middle ear effusion”. Ear Nose Throat J, 89: 434-437.

Sheahan, P. et al. (2002): "Sequelae of otitis media with effusion among children with cleft lip and/ or cleft palate”. Clin Otolaryngol, 27: 494-500.

Shekelle, P. et al. (2002): "Diagnosis, natural history, and late effects of otitis media with effusion”. Evid Rep Technol Assess (Summ), (55): I-5.

Shiao, A. S. y Guo, Y. C. (2005): “A comparison assessment of videotelescopy for diagnosis of pediatric otitis media with effusion". Int J Pediatr Otorhinolaryngol, 69 (I I): I497-I 502.

SIGN (2003): Diagnosis and management of childhood otitis media in primary care. Scottish Intercollegiate Guidelines Network (en línea). <http://www.sign.ac.uk/pdf/sign66.pdf>, acceso 20 de junio de 2016.

Simpson, S. A. et al. (20I I): "Oral or topical nasal steroids for hearing loss associated with otitis media with effusion in children". Cochrane Database Syst Rev, 5: CDooI93 5.

Simpson, S. A. et al. (2007): "Identification of children in the first four years of life for early treatment for otitis media with effusion". Cochrane Database Syst Rev, I: CDoo4I63.

Skovbjerg, S. et al. (2009): “Spray bacteriotherapy decreases middle ear fluid in children with secretory otitis media". Arch Dis Child, 94: 92.

Stool, S. E. et al. (1994): Otitis media with effusion in young children: clinical practice guideline no. I 2. Rockville, M. D.: Agency for Healthcare Research and Quality.

Tawfik, S.A. et al. (2016): "Role of bacterial biofilm in development of middle ear effusion". Eur Arch Otorhinolaryngol, 273 (I I): 40034009 .

Thomas, C. L. et al. (2006): "Oral or topical nasal steroids for hearing loss associated with otitis media with effusion in children". Cochrane Database Syst Rev, 3: CDoor935.

Todberg, T. et al. (2OI4): "Incidence of otitis media in a contemporary Danish National Birth Cohort”. PLOS One, 9: eIII732.

Torres, S. (2016): "Entrevista a Santiago Torres". Revista FIAPAS, I 57: I4-I7.

Torres, S. (2004a): "Fundamentos lingüísticos e intervención logopédica”, en Jáudenes, C. et al. (dir.): Manual básico de formación especializada sobre discapacidad auditiva. Madrid: Confederación Española de Familias de Personas Sordas-FIAPAS.

Torres, S. (2004b): "Fundamentos para la intervención en el desarrollo del lenguaje oral y escrito", en Jáudenes, C. et al. (dir.): Manual básico de formación especializada sobre discapacidad auditiva. Madrid: Confederación Española de Familias de Personas Sordas-FIAPAS.

Van Balen, F. A. y De Melker, R. A. (2000): "Persistent otitis media with effusion: can it be 
predicted? A family practice follow-up study in children aged 6 months to 6 years". J Fam Pract, 49 (7): 605-6II.

Van Hoecke, H. et al. (2016): "Haemophilus influenzae biofilm formation in chronic otitis media with effusion". Eur Arch Otorhinolaryngol, 273 (II): 3553-3560.

Van Zon, A. et al. (2012): "Antibiotics for otitis media with effusion in children”. Cochrane Database Syst Rev, 9: CDoogr63.

Venekamp, R. P. et al. (2016): "Antibiotics for otitis media with effusion in children". Cochrane Database Syst Rev, (6): CDoogr63.

Venekamp, R. P. et al. (2OI 5): “Antibiotics for acute otitis media in children". Cochrane Database Syst Rev, (6): CDooo2I9.

Villalba, A. (2004): "Implicaciones de la sordera: repercusiones en el desarrollo lingüístico, cognitivo, afectivo y social", en Jáudenes, C. et al. (dir.): Manual básico de formación especializada sobre discapacidad auditiva. Madrid: Confederación Española de Familias de Personas Sordas-FIAPAS.

Vlastarakos, P. V. et al. (2007): "Grommets in otitis media with effusion: the most frequent operation in children. But is it associated with significant complications?”. Eur J Pediatr, I 66 (5):385-39I.

Wallace, I. F. et al. (20I4): "Surgical treatments for otitis media with effusion: a systematic review”. Pediatrics, I33 (2): 296-3 I I.

Williams, R. L. et al. (I993): "Use of antibiotics in preventing recurrent acute otitis media and in treating otitis media with effusion. A meta- analytic attempt to resolve the brouhaha". JAMA, 270: I344.

Williamson, I. et al. (20I 5 a): "Effect of nasal balloon autoinflation in children with otitis media with effusion in primary care: an open randomized controlled trial”. CMAJ, I87:96I969.

Williamson, I. et al. (2OI 5 b): “An open randomised study of autoinflation in 4 to I I year-old school children with otitis media with effusion in primary care". Health Technol Assess, I9: I-I 50 .

Williamson, I. (20II): "Otitis media with effusion in children”. BMJ Clin Evid, 201 I: 0502.

Williamson, I. et al. (2009): “A double-blind randomized placebo-controlled trial of topical intranasal corticosteroids in 4 to I I year-old children with persistent bilateral otitis media with effusion in primary care". Health Technol Assess (Winch Eng), I3: I-I44.

Williamson, I. (2002): "Otitis media with effusion”. Clin Evid, 7: 469-476.

Williamson, I. et al. (I994): "The natural history of otitis media with effusion: a three-year study of the incidence and prevalence of abnormal tympanograms in four South West Hampshire infant and first schools". J Laryngol Otol, ı०8: 930-934.

Zielnik, B. y Stankiewicz, W. (20I6): "Evaluation of the interleukin-I receptor antagonist and immunoregulatory interleukin-ıo in the middle ear in chronic otitis media with effusion in children with and without atopy clin exp". Otorhinolaryngol, 9: 104-108. 